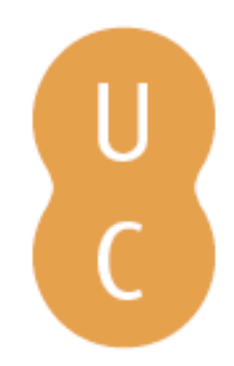

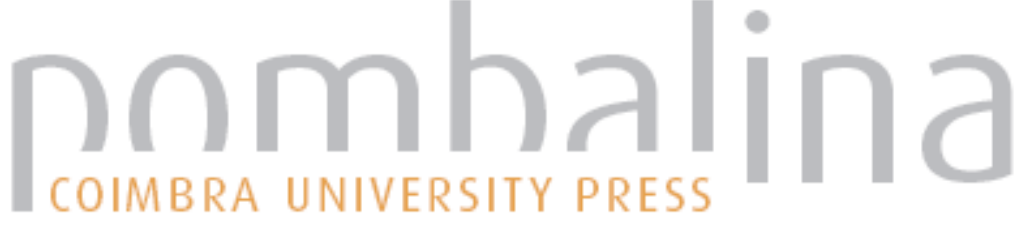

\section{Infeções das vias respiratórias inferiores}

\author{
Autor(es): $\quad$ Mação, Patrícia
}

Publicado por: Imprensa da Universidade de Coimbra

URL

persistente: URI:http://hdl.handle.net/10316.2/43120

DOI: $\quad$ DOI:https://doi.org/10.14195/978-989-26-1300-0_19

Accessed : $\quad$ 26-Apr-2023 12:39:01

A navegação consulta e descarregamento dos títulos inseridos nas Bibliotecas Digitais UC Digitalis, UC Pombalina e UC Impactum, pressupõem a aceitação plena e sem reservas dos Termos e Condições de Uso destas Bibliotecas Digitais, disponíveis em https://digitalis.uc.pt/pt-pt/termos.

Conforme exposto nos referidos Termos e Condições de Uso, o descarregamento de títulos de acesso restrito requer uma licença válida de autorização devendo o utilizador aceder ao(s) documento(s) a partir de um endereço de IP da instituição detentora da supramencionada licença.

Ao utilizador é apenas permitido o descarregamento para uso pessoal, pelo que o emprego do(s) título(s) descarregado(s) para outro fim, designadamente comercial, carece de autorização do respetivo autor ou editor da obra.

Na medida em que todas as obras da UC Digitalis se encontram protegidas pelo Código do Direito de Autor e Direitos Conexos e demais legislação aplicável, toda a cópia, parcial ou total, deste documento, nos casos em que é legalmente admitida, deverá conter ou fazer-se acompanhar por este aviso.

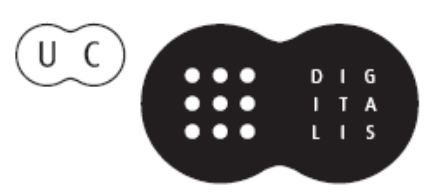


Capítulo 19.

Infeções das vias respiratórias inferiores
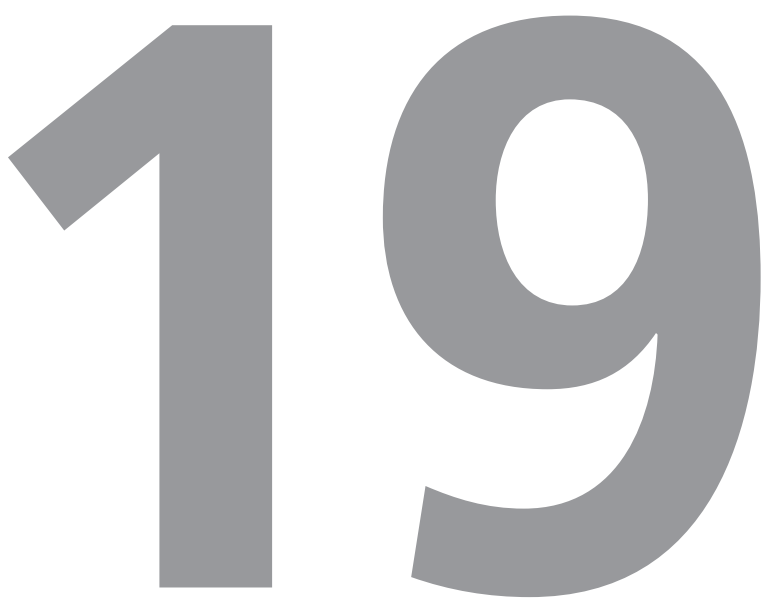

\section{Patrícia Mação}




\subsection{CONTEXTO}

As doenças respiratórias, nomeadamente as de causa infeciosa, são muito frequentes em idade pediátrica. A bronquiolite aguda (BQL) e a pneumonia adquirida na comunidade (PAC), que se localizam ao aparelho respiratório baixo serão abordadas nesta lição.

\subsection{DESCRIÇÃO DO TEMA}

\subsubsection{Bronquiolite aguda}

A BQL é uma infeção que atinge as vias respiratórias de pequeno calibre, que afeta sobretudo crianças abaixo dos dois anos de idade (pico de incidência entre os três e os seis meses), manifestando-se tipicamente com um quadro de pieira febril. O seu diagnóstico geralmente reserva-se ao primeiro episódio de pieira, não devendo ser considerado em situações de pieira repetida.

A etiologia é predominantemente vírica, sendo o vírus sincicial respiratório (VSR) responsável pela maioria dos casos (50 a 80\%). Outros vírus podem também estar implicados como: rinovírus, parainfluenza 1, 2 e 3, metapneumovírus, influenza $A$ e $B$, adenovírus e bocavírus. A co-infeção viral é comum (1/3 dos casos), podendo constituir um fator de risco de gravidade. Existem também relatos de infeções respiratórias e episódios de pieira em lactentes associados ao Mycoplasma pneumoniae.

A infeção tem caracteristicamente um carácter sazonal, com um pico de incidência no outono e inverno.
A transmissão ocorre por contacto direto com partículas aerossolizadas que contêm o vírus ou através de fomites, geralmente nos primeiros seis dias de doença.

A infeção pelo vírus causa lesão direta das células do epitélio respiratório, destruição das células ciliadas e inflamação dos pequenos brônquios e bronquíolos (infiltração linfocitária). O edema, acumulação de muco e a descamação de células mortas levam a obstrução das pequenas vias aéreas, atelectasias e consequentemente perturbação da capacidade de ventilação-perfusão pulmonar. As lesões ciliares podem persistir por duas semanas.

\section{O curso da doença caracteriza-se por:}

- Fase inicial (dois a três dias): sintomas nasais predominantes e febre;

- Fase de agravamento (terceiro a quinto dias): tosse seca, por vezes por acessos, aumento da frequência respiratória e da dificuldade respiratória (tiragem, adejo nasal) e hiperinsuflação torácica (aumento do diâmetro antero-posterior do tórax) e a auscultação pulmonar apresenta de início aumento do tempo expiratório seguido de sibilos e/ou fervores;

- Fase de melhoria (quinto a sétimo dias): podendo a tosse persistir.

Em ex-prematuros e pequenos lactentes (menos de dois meses) a apneia pode ser a primeira manifestação.

A evolução clínica é variável, sendo na maioria dos casos autolimitada e benigna. A duração 


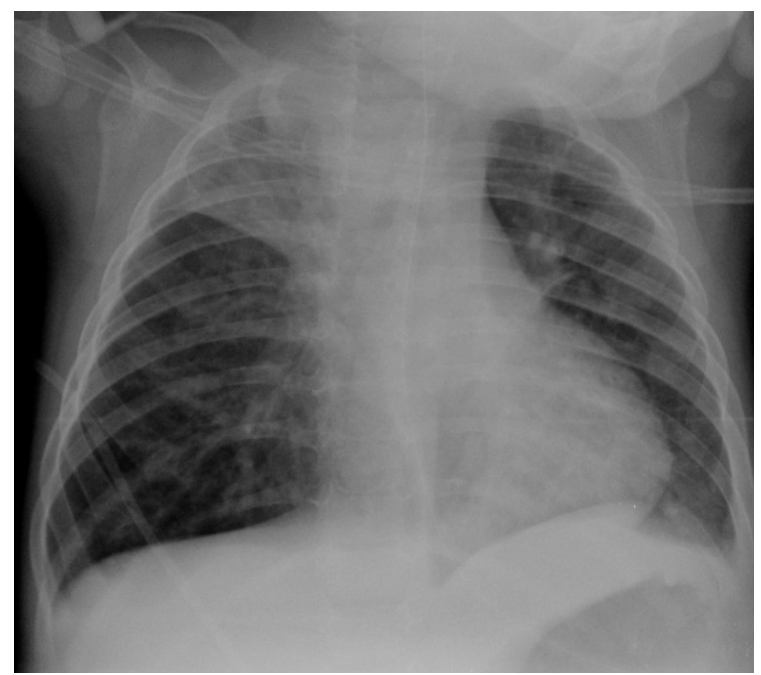

Figura 1. Hiperinsuflação e atelectasia do lobo superior direito. Imagem do autor.

da doença é em média uma semana, no entanto podem persistir sintomas respiratórios como tosse durante mais de quatro semanas em 10\% dos casos, dependendo da idade, da gravidade da doença, das co-morbilidades de alto risco e do agente etiológico.

O diagnóstico de BQL é clínico, baseado na anamnese, nas alterações no exame objetivo, na idade da criança e na epidemiologia. Os exames complementares de diagnóstico só estão indicados em casos particulares.

A realização de radiografia do tórax pode ser considerada se a evolução for atípica, se houver dúvidas no diagnóstico ou evidência de complicações. As alterações radiológicas são variáveis e inespecíficas, e incluem sinais de hiperinsuflação pulmonar com horizontalização dos arcos costais e abaixamento do diafragma, atelectasias, áreas de espessamento peribrônquico e opacidades

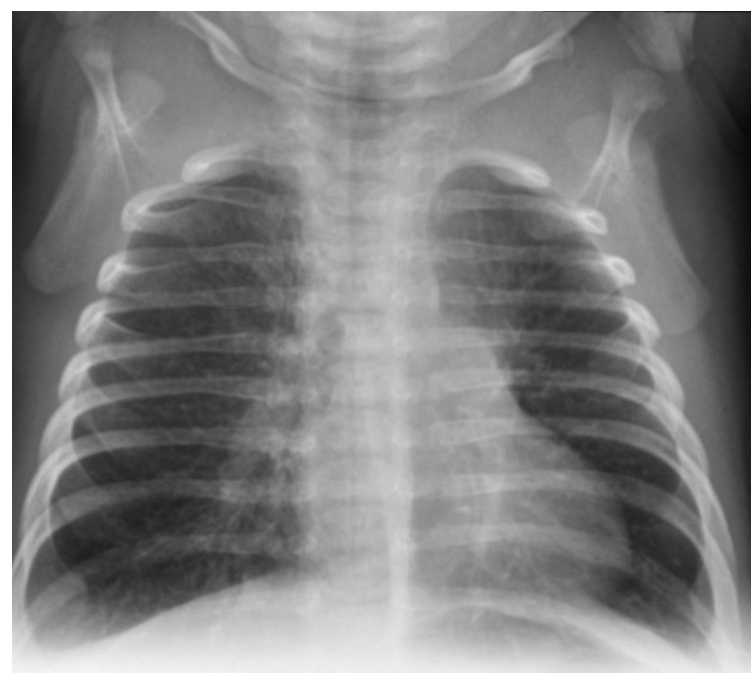

Figura 2. Hiperinsuflação e horizontalização dos arcos costais. Imagem do autor.

(segmentar ou mesmo lobar), que podem ser confundidas com pneumonia, Figuras 1 e 2.

Os testes rápidos para identificação de antigénios virais (Imunofluorescência ou EnzymeLinked Immunosorbent Assay) e as técnicas moleculares de diagnóstico viral (Polimerase chain reaction - PCR) efetuados nas secreções brônquicas ou da orofaringe permitem conhecer o agente etiológico, mas devem ser utilizados apenas em estudos epidemiológicos ou de investigação e pela possibilidade de isolamento do doente internado com BQL.

A gasometria é útil apenas no doente com critérios de internamento em cuidados intensivos.

O hemograma, doseamento da proteína C reativa e estudos bacteriológicos (cultura de secreções brônquicas, hemocultura, urocultura) podem ser utilizados na suspeita de complicações 
ou infeções bacterianas associadas (i.e. bacteriémia, meningite, infeção urinária).

O ionograma sérico e urinário pode ser necessário em casos graves em que se suspeita de alterações hidroelectrolíticas por Secreção Inapropriada de Hormona Antidiurética (SIHAD).

Na grande maioria dos casos o quadro clínico de BQL é tão óbvio que não se impõe qualquer diagnóstico diferencial. Contudo nos casos de pieira recorrente, nas formas clínicas atípicas ou sem contexto epidemiológico devem considerar-se outras entidades como: asma, pneumonia, tosse convulsa, aspiração de corpo estranho, refluxo gastro-esofágico, insuficiência cardíaca e causas anatómicas de compressão das vias aéreas como é o caso de um anel vascular.

A história clínica detalhada, incluindo antecedentes pessoais e familiares e um bom exame objetivo são essenciais e suficientes para o diagnóstico.

A BQL evolui habitualmente sem complicações.

Em casos mais graves e, sobretudo, em doentes com fatores de risco (quadro 1), a probabilidade de complicações aumenta, das quais se destacam: desidratação, atelectasia, insuficiência respiratória e infeções bacterianas secundárias, nomeadamente otite média aguda e pneumonia. O risco de infecção urinária, bacteriémia ou meningite associada é muito baixo.

A hiponatrémia por síndrome de SIHAD também está descrita como complicação de BQL, e o seu risco aumenta com a utilização de fluídos endovenosos, em particular soros hipotónicos.

Apenas uma pequena percentagem de doentes com BQL (inferior a 5\%) necessita de internamento hospitalar. Os critérios para internamento estão descritos no quadro 2.
- Idade inferior a 12 semanas.

- História de prematuridade (idade gestacional inferior a 37 semanas).

- Cardiopatia congénita.

- Doença pulmonar crónica do lactente (displasia broncopulmonar, fibrose quística, doença pulmonar difusa ou congénita).

- Doença neuromuscular ou neurológica grave.

- Imunodeficiência.

- Trissomia 21.

- Exposição ao fumo de tabaco.

Quadro 1. Fatores de risco para complicações da bronquiolite aguda.

Após ter sido realizado o diagnóstico de BQL deve ser efetuada uma avaliação da gravidade da doença, com implicações na orientação terapêutica. Após desobstrução nasal, deve registar-se

- Idade inferior a 6 semanas.

- Saturação periférica de Oxigénio $\leq$ 92\%.

- Incapacidade alimentar.

- Dificuldade respiratória moderada a grave ou em agravamento e hipoxemia.

- Existência de fatores de risco para maior gravidade.

- Incapacidade dos familiares para prestação de cuidados e vigilância adequados ou dificuldade no acesso aos serviços de saúde.

Quadro 2. Critérios de internamento de doentes com bronquiolite aguda. 
então: a frequência respiratória (FR), medida durante um minuto; o impacto na alimentação e grau de hidratação; a presença de apneia (baseada na observação ou história sugestiva, sobretudo se a idade for inferior a seis semanas); a hipoxémia determinada por oxímetro de pulso; a frequência cardíaca; o estado de consciência; o grau de dificuldade respiratória com base na presença de tiragem, incapacidade para vocalização ou gemido; e o grau de ventilação apreciado pela expansão torácica e auscultação pulmonar.

Existem múltiplas escalas clínicas que foram desenvolvidas para avaliar a gravidade da doença em contexto de investigação, no entanto na prática clínica a sua utilidade é limitada.

Na maioria dos casos de BQL são suficientes medidas de suporte para manter a oxigenação e hidratação.

As orientações atuais, da Associação Americana de Pediatria (AAP) publicadas em 2014 e a norma da Direção-Geral da Saúde (DGS) atualizada em 2015, recomendam para o doente internado:

- Oxigenoterapia: quando se verifique $\mathrm{SpO}_{2}$ inferior ou igual a 90 a 92\% com ar ambiente;

- Hidratação: adequada às necessidades hídricas, por sonda naso-gástrica, na criança com dificuldade respiratória progressiva ou incapacidade alimentar; e em alternativa por via endovenosa, particularmente no doente crítico.

Na alta para o domicílio há que explicar a evolução natural da doença e dos sinais de alarme para reobservação médica e como medidas terapêuticas: a desobstrução nasal (utilização de soro fisiológico nasal, sem recurso a fármacos descongestionantes); elevação da cabeceira da cama/berço a $30^{\circ}$ e manutenção de bom estado de hidratação e nutrição através de fracionamento das refeições.

Não está provada a eficácia de nebulizações com salbutamol, adrenalina, brometo de ipratrópio, ou soro salino hipertónico. Estas medidas terapêuticas podem ser consideradas em casos individuais, sob vigilância médica.

Os corticóides, cinesiterapia respiratória e os antibióticos também não estão indicados.

Em casos de maior gravidade, a prescrição de oxigénio de alto fluxo (aquecido e humidificado) ou ventilação não invasiva, pode ser efetuada em algumas unidades hospitalares, de acordo com a preparação da respetiva unidade e com os protocolos específicos.

O prognóstico é favorável na grande maioria dos doentes.

A prevenção da BQL, quer na comunidade, quer associada aos cuidados de saúde, é fundamental.

Salienta-se a importância da lavagem das mãos antes e após o contacto com os doentes na redução da transmissão da doença. É recomendada também a limitação de contactos com os doentes e o internamento em quartos de isolamento nos casos em que seja isolado o VSR. A evicção do tabagismo passivo, que aumenta a suscetibilidade e agrava o prognóstico da doença, e o incentivo do aleitamento materno que se associa a menor gravidade e taxas mais reduzidas de internamento, são cuidados que se devem fomentar. 
A nível nacional e internacional, as sociedades de Pediatria recomendam a utilização preventiva de palivizumab (anticorpo monoclonal humano recombinante, específico contra VSR) em grupos de risco (antecedentes de prematuridade, displasia broncopulmonar ou cardiopatia) dado que reduz as taxas de hospitalização e a gravidade da doença. Está recomendada a administração por via intramuscular de cinco doses mensais na época fria, com início em novembro.

\subsubsection{Pneumonia adquirida na comunidade}

O termo pneumonia refere-se ao processo inflamatório que envolve os pulmões, nomeadamente os alvéolos, pleura visceral, tecido conjuntivo, vias aéreas, alvéolos e estruturas vasculares adjacentes. Trata-se de uma infeção e caracteriza-se por febre e/ou sintomas e sinais respiratórios de início recente e evidência de envolvimento do parênquima pulmonar (alterações no exame físico ou presença de opacidades na radiografia do tórax).

Por adquirida na comunidade entende-se que a infeção foi adquirida fora do ambiente hospitalar, isto é, a criança não esteve internada nos sete dias que precedem o diagnóstico ou estava internada há menos de 48 horas.

A pneumonia adquirida na comunidade (PAC) ocorre em todo o ano, embora seja mais frequente nos meses frios, dada a maior circulação de vírus (VSR e influenza) e à maior permanência das crianças em espaços fechados.

Um grande número de microrganismos estão implicados na etiologia da PAC. A identificação do agente etiológico muitas vezes não é possível, tendo em conta a dificuldade na obtenção de amostras adequadas e a baixa produtividade das técnicas diagnósticas utilizadas.

Os principais agentes etiológicos da PAC são os vírus respiratórios, nomeadamente VSR, influenza A e B, parainfluenza, adenovírus, metapneumovírus humano e rinovírus. Em crianças abaixo dos dois anos os vírus foram identificados em até $80 \%$ dos casos de PAC, isoladamente ou em associação. A sua importância diminui com a idade, sendo responsáveis por apenas um terço dos casos em crianças com mais de cinco anos. A etiologia varia com a idade, estando os agentes mais frequentes referidos no quadro 3.

Apesar da imunização com a vacina anti-pneumocócica conjugada ter diminuído a incidência da doença por este gérmen, o Streptococcus pneumoniae $(S p)$ continua a ser a bactéria mais frequentemente implicada na etiologia de PAC em crianças.

Pelo contrário, as infeções por Haemophilus influenzae tipo b (Hib) foram virtualmente eliminadas nos países em que a vacinação é obrigatória e universal, devendo contudo ser consideradas em pequenos lactentes não completamente imunizados.

O Staphylococcus aureus (Sa) e o Streptococcus pyogenes (Spy) são causas raras de PAC em crianças previamente saudáveis. Manifestam-se como pneumonias muito graves. Está bem descrita a associação de pneumonia estafilocócica secundária a infeção por vírus influenza.

A tosse convulsa, causada pela Bordetella pertussis $(B p)$, constitui um importante problema de saúde pública. Os pequenos lactentes com cobertura vacinal parcial ou ausente constituem o 


\begin{tabular}{|c|c|c|}
\hline $\begin{array}{l}\text { Pequeno lactente } \\
\text { (1 a } 3 \text { meses) }\end{array}$ & $\begin{array}{l}\text { Lactente e } \\
\text { idade pré-escolar } \\
\text { (4 meses a } 4 \text { anos) }\end{array}$ & $\begin{array}{l}\text { Criança mais velha e } \\
\text { adolescente ( } \geq 5 \text { anos ) }\end{array}$ \\
\hline $\begin{array}{l}\text { Vírus respiratórios } \\
\text { Streptococcus pneumoniae (Sp) } \\
\text { Chlamydia trachomatis } \\
\text { Bordetella pertussis }\end{array}$ & $\begin{array}{l}\text { Vírus respiratórios } \\
\mathrm{Sp}\end{array}$ & $\begin{array}{l}\text { Mycoplasma pneumoniae } \\
\text { Sp } \\
\text { Vírus respiratórios }\end{array}$ \\
\hline
\end{tabular}

PAC - Pneumonia adquirida na comunidade, Sp - Streptococcus pneumoniae. Adaptado de Manual of Childhood Infections: The Blue Book, 4th Edition, 2016

Quadro 3. Distribuição dos agentes etiológicos mais frequentes de PAC de acordo com a idade.

grupo mais vulnerável para complicações graves, nas quais se inclui a pneumonia.

A pneumonia surge na sequência do compromisso do sistema imunitário do hospedeiro, invasão por um agente virulento e/ou invasão por grande quantidade de inóculo. Essa invasão pode ocorrer através de diferentes vias: via áerea, por inalação ou microaspiração (a mais frequente) ou por via hematogénica. Os mecanismos de defesa pulmonares são do tipo mecânico (reflexo da tosse e depuração mucociliar) ou do tipo imunológico (ação de imunoglobulinas, destruição bacteriana pelo complemento, opsonização, ingestão macrofágica e imunidade celular). A falência em qualquer destes mecanismos desencadeia uma cascata inflamatória e leva à redução da compliance pulmonar, aumento da resistência, obstrução das pequenas vias aéreas, e pode resultar em colapso das vias respiratórias distais, air trapping (retenção de ar) e alteração da ventilação-perfusão pulmonar. As infecções graves estão associadas a necrose do epitélio brônquico, dos bronquíolos e/ou do parênquima pulmonar.

\section{As manifestações clínicas de pneumonia} variam de acordo com a etiologia, as características do hospedeiro e a gravidade da doença.

A tríade clínica clássica da pneumonia pneumocócica e constituida por febre de início súbito/agudo, taquipneia e tosse, no entanto, os sintomas podem ser variados e inespecíficos, particularmente numa fase inicial da doença e em pequenos lactentes. Nestes, a recusa alimentar, irritabilidade e gemido podem ser a forma de apresentação.

A febre é uma manifestação frequente, e pode ser o único sinal de pneumonia em crianças pequenas. Mas nos pequenos lactentes, pode não haver febre.

Após o primeiro mês de vida a tosse é o sintoma mais comum. No caso particular da PAC de etiologia pneumocócica a tosse pode estar ausente na fase inicial da doença, dado que esta surge apenas quando há atingimento dos recetores das vias aéreas, localizados a nível dos brônquios e bronquíolos.

Outros sinais respiratórios (i.e. taquipneia) podem preceder a tosse. A taquipneia é o sinal 


\begin{tabular}{|c|c|c|c|}
\hline Tipo de pneumonia & Bacteriana (típica) & Bacteriana (atípica) & Viral \\
\hline Gérmen & $\mathrm{Sp}$ & $\mathrm{Mp}$ & Vírus respiratórios \\
\hline Idade & Qualquer & Superior a 5 anos & Inferior a 5 anos \\
\hline Início & Súbito & Gradual & Gradual \\
\hline $\begin{array}{l}\text { Contexto } \\
\text { epidemiológico }\end{array}$ & Não & Frequente & Frequente, em simultâneo \\
\hline Febre & Sim, superior a $39^{\circ} \mathrm{C}$ & Não ou inferior a $38,5^{\circ} \mathrm{C}$ & $\operatorname{sim}$ \\
\hline Tosse & $\begin{array}{l}\text { Ausente no início, } \\
\text { depois produtiva }\end{array}$ & $\begin{array}{l}\text { Agravamento } \\
\text { progressivo, acessual }\end{array}$ & Seca \\
\hline Sinais associados & Dor pleurítica & $\begin{array}{l}\text { Cefaleias, mialgias e } \\
\text { sintomas constitucionais }\end{array}$ & $\begin{array}{l}\text { Coriza, conjuntivite, } \\
\text { mialgias }\end{array}$ \\
\hline Exame objetivo & $\begin{array}{l}\text { "Ar doente". } \\
\text { Diminuição MV e } \\
\text { crepitações localizadas. } \\
\text { Sopro tubário. }\end{array}$ & $\begin{array}{l}\text { Crepitações e/ou sibilos } \\
\text { uni ou bilaterais }\end{array}$ & $\begin{array}{l}\text { Crepitações e } \\
\text { sibilos bilaterais }\end{array}$ \\
\hline
\end{tabular}

Sp - Streptococus pneumoniae, Mp - Mycoplasma pneumoniae, MV - Murmúrio vesicular.

Quadro 4. Manifestações clínicas de pneumonia em relação com o agente etiológico.

mais sensível e específico de pneumonia, e a sua ausência permite praticamente excluir o diagnóstico. Não esquecer que a frequência respiratória é variável em função da idade, da temperatura e da ansiedade da criança.

As crianças mais velhas podem referir dor torácica pleurítica (agrava com a respiração) e em alguns casos dor abdominal (dor referida dos lobos inferiores do pulmão) ou também dor no ombro ou rigidez da nuca, quando a pneumonia se localiza aos lobos superiores.

Como já foi referido, o quadro clínico não é suficientemente específico para estabelecer o diagnóstico etiológico da pneumonia, no entanto alguns achados podem ser mais sugestivos de determinada etiologia (quadro 4).

Após colheita da anamnese, deve ser efetuado um exame objetivo completo com destaque para a avaliação do estado geral do doente, do grau de hidratação, e dos sinais de síndrome de dificuldade respiratória (presença de pelo menos dois dos sinais clínicos: taquipneia, tiragem, adejo nasal, gemido e cianose).

A oximetria de pulso, é um método objetivo de avaliação da saturação periférica de oxigénio, recomendado nos doentes com sinais de dificuldade respiratória.

O diagnóstico de PAC é essencialmente clínico. Não há indicação para a realização de exames complementares de diagnóstico por rotina em crianças que não apresentem critérios de internamento.

A radiografia do tórax pode ser útil para confirmar o diagnóstico e avaliar a existência de complicações. A incidência habitualmente recomendada é a postero-anterior, uma vez que permite melhor visualização do 


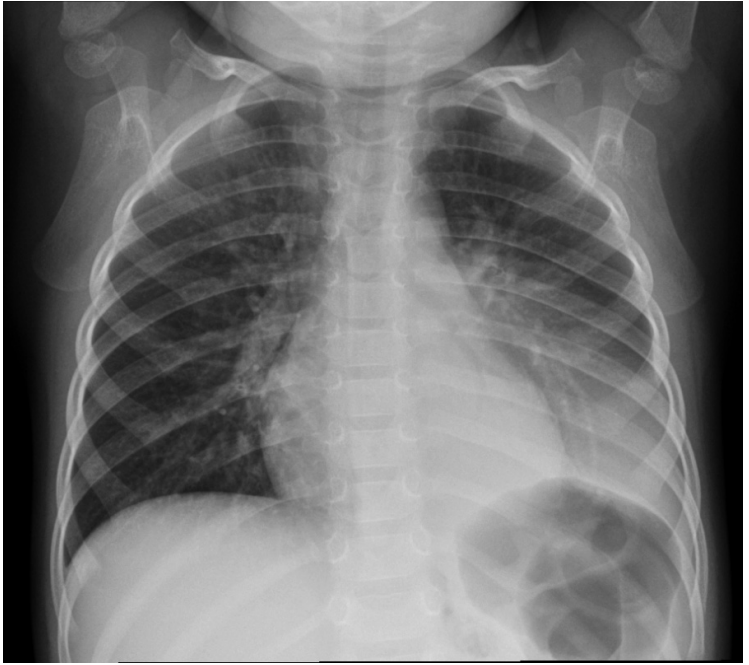

Figura 3. Condensação lobar no hemitórax esquerdo, com broncograma aéreo. Imagem do autor.

campo pulmonar ao reduzir a sombra cardíaca. As incidências laterais não devem ser efetuadas por rotina, porque não aumentam a acuidade diagnóstica e não têm utilidade no tratamento. Nem sempre existe correlação entre os achados radiológicos e a clínica, sobretudo nas primeiras horas de evolução da doença e em lactentes e crianças mais pequenas.

Podem ser descritos vários padrões radiológicos, que se associam a um determinado agente etiológico, embora não sejam específicos. Classicamente os padrões radiológicos dividem-se em três tipos:

- Alveolar: caracterizado por uma consolidação lobar ou segmentar, geralmente única e broncograma aéreo, associado a Sp, Figura 3;

- Intersticial: reforço broncovascular, proeminência a nível peri-hilar e

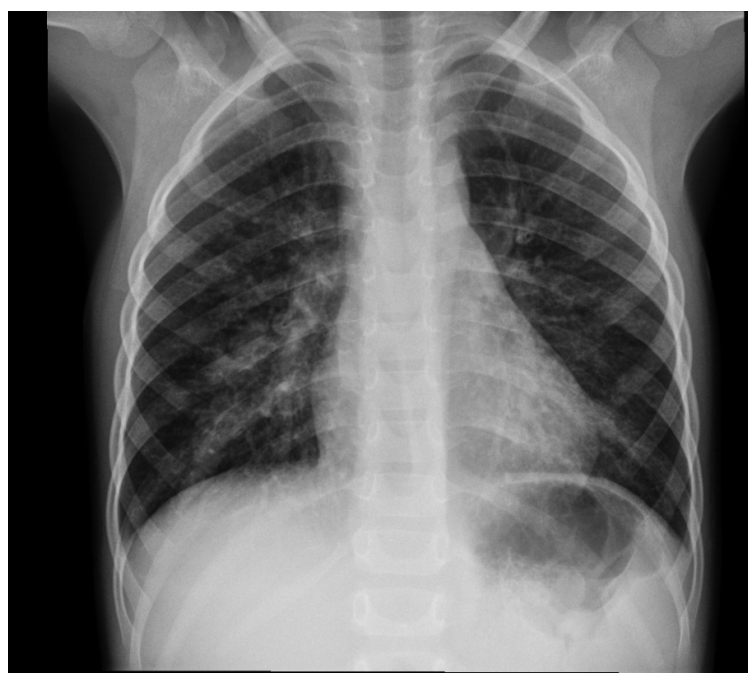

Figura 4. Infiltrado intersticial bilateral com reforço peri-hilar. Imagem do autor.

hiperinsuflação, associado a vírus respiratórios e Mp, Figura 4;

- Broncopneumonia: padrão bilateral difuso, reforço peribrônquico e pequenos infiltrados nodulares que se distendem até à periferia, geralmente associada a Sa e outras bactérias, Figura 5.

Em circunstâncias especiais, poderá ser realizada ecografia torácica, nomeadamente para confirmação ou caracterização de derrame pleural.

O hemograma e os marcadores de infeção de fase aguda (rastreio sético) são pouco específicos. Podem ser efetuados em casos graves ou com necessidade de internamento.

Nas PAC de etiologia pneumocócica há frequentemente leucocitose com predomínio de polimorfonucleares e os marcadores de infeção de fase aguda estão muito aumentados. Porém a leucocitose não é específica das infeções bacterianas 


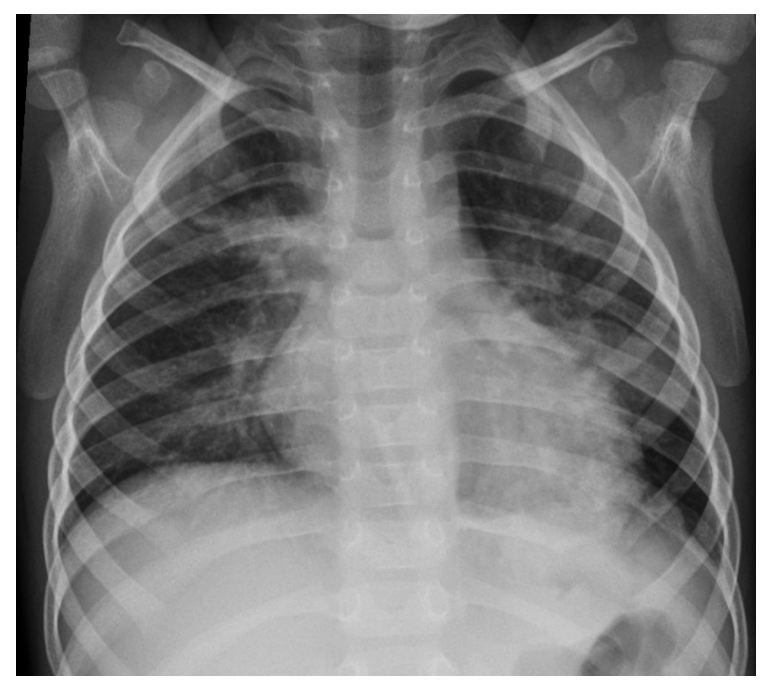

Figura 5. Padrão bilateral difuso, reforço peribrônquico e pequenos infiltrados nodulares que se estendem à periferia. Imagem do autor.

e também pode estar presente nas pneumonias causadas por vírus (adenovírus e influenza). No caso particular da tosse convulsa $(B p)$ é frequente existir leucocitose marcada com predomínio de linfócitos (reação leucemóide).

Os marcadores de infeção de fase aguda (proteína $C$ reactiva e procalcitonina) não permitem isoladamente distinguir a etiologia da pneumonia. Podem ser úteis durante a evolução da doença para avaliar a resposta à terapêutica.

A velocidade de sedimentação é um exame dispensável, dada a sua elevação e diminuição lentas.

Avaliar o ionograma e os biomarcadores séricos de função renal (ureia e creatinina) pode ser útil em doentes com sinais de desidratação e com suspeita de SIHAD.

A investigação etiológica específica deve ser considerada nas crianças com quadros graves, quando a evolução clínica não é típica ou quando há complicações, e por razões epidemiológicas (suspeita de surto/epidemia).

A hemocultura é um exame muito específico mas pouco sensível, sendo positiva em apenas $10 \%$ dos quadros de PAC. Está indicada em casos com necessidade de internamento, antes de iniciar antibioterapia empírica, ou quando a evolução não é favorável.

Os testes rápidos para deteção dos antigénios virais ou as técnicas de biologia molecular efetuadas no exsudado da nasofaringe podem auxiliar na decisão terapêutica e de medidas de isolamento nos doentes internados, particularmente nos casos suspeitos de agente vírico ou atípico.

Salienta-se que a identificação viral e bacteriana na nasofaringe pode não refletir o agente causal da PAC, mas antes agentes colonizadores da nasofaringe, não sendo rara a identificação de múltiplos agentes.

Os testes serológicos permitem apenas confirmar a etiologia a posteriori, não estando por isso indicados por rotina.

A deteção de antigénios capsulares do Sp na urina não deve ser efetuada, porque não permite distinguir a infeção do estado de portador, frequente em crianças menores de cinco anos.

O exame bacteriológico do líquido pleural (no caso de derrame) e do lavado bronco-alveolar são o método mais eficaz para identificar o agente etiológico da pneumonia, no entanto são muito invasivos, e por isso, reservados para situações graves que não respondem à terapêutica instituída.

O diagnóstico diferencial de pneumonia infeciosa deve ser equacionado em crianças que não respondem à terapêutica e têm formas de apresentação ou evolução atípicas. 
Os diagnósticos a considerar são: aspiração de corpo estranho, bronquiolite.

A maioria dos casos de PAC resolve sem complicações.

As complicações mais frequentes são: derrame pleural, pneumonia necrotizante, abcesso pulmonar e hiponatrémia. São muito mais frequentes nas infeções bacterianas, embora também estejam descritas em casos de pneumonias associadas a infeções por bactérias atípicas e vírus.

A decisão terapêutica nos doentes com PAC deve ser tomada tendo em conta a idade, a clínica e os fatores epidemiológicos. O tratamento deve sempre incluir medidas gerais de controlo da febre e dor, e oxigenação adequadas.

Quando efetuado em ambulatório, devem sempre ser dadas indicações á família para controlo da febre e dor, e identificação de sinais de deterioração clínica. Os critérios de internamento estão descritos no quadro 5.

Na PAC a cinesiterapia respiratória não está indicada e a manipulação da criança deve ser mínima.

A antibioterapia por via oral é segura e eficaz, sendo a recomendada em primeira linha. A utilização da via endovenosa reserva-se para casos em que a criança apresente um quadro de sépsis, pneumonia complicada ou incapacidade de absorção oral (vómitos).

A escolha do antibiótico, quando é decidida a sua prescrição, deve ter também em linha de conta o padrão esperado de sensibilidade aos antimicrobianos já que raramente o agente etiológico é identificado. No quadro 6 especifica-se os esquemas terapêuticos recomendados por grupo etário.
- Idade inferior a quatro meses.

- Dificuldade respiratória significativa.

- Hipoxémia (SpO2 inferior a 92\%).

- "Ar tóxico".

- PAC complicada.

- Doença crónica subjacente que aumenta o risco de evolução desfavorável.

- Sinais de desidratação ou incapacidade de alimentação (inferior a dois terços do habitual).

- Falência do tratamento ambulatório.

- Incapacidade dos familiares para prestação de cuidados e vigilância adequada.

SpO2 - Saturação periférica de oxigénio; PAC - Pneumonia adquirida na comunidade. Adaptado de "Norma 019/2012. Diagnóstico e Tratamento da Pneumonia Adquirida na Comunidade em Idade Pediátrica. Direção-Geral da Saúde".

Quadro 5. Critérios de internamento de doentes com PAC.

O antibiótico de primeira linha para tratamento de PAC bacteriana é a amoxicilina, exceto quando há forte suspeita inicial de $M p$, Chlamydophila pneumoniae ou outro gérmen específico e potencialmente mais agressivo (i.e. Sa).

A dose de amoxicilina deve ser elevada (80 a $90 \mathrm{mg} / \mathrm{kg} / \mathrm{dia}$ ) para ser eficaz contra os pneumococos com resistência intermédia à penicilina.

A duração do tratamento é em geral de sete a dez dias. Nos casos de PAC grave ou complicada podem ser necessários períodos de antibioterapia mais prolongados.

A terapêutica antiviral com o oseltamivir (inibidores da neuraminidase) pode ser considerada em alguns casos de infeção por influenza. As 


\begin{tabular}{|c|c|c|c|c|}
\hline Idade & $\begin{array}{l}\text { Antibiótico de } \\
\text { primeira linha }\end{array}$ & Dose, posologia & $\begin{array}{l}\text { Antibiótico } \\
\text { alternativo }\end{array}$ & Dose, posologia \\
\hline \multirow[t]{2}{*}{1 a 3 meses } & $\begin{array}{l}\text { Amoxicilina PO } \\
\text { Ampicilina EV }\end{array}$ & $\begin{array}{l}90 \mathrm{mg} / \mathrm{kg} / \mathrm{dia}, 3 \mathrm{id} \\
150 \text { a } 200 \mathrm{mg} / \mathrm{kg} / \mathrm{dia}, 3-4 \mathrm{id}\end{array}$ & $\begin{array}{l}\text { Amox-clav PO } \\
\text { Ceftriaxone EV }\end{array}$ & $\begin{array}{l}90 \mathrm{mg} / \mathrm{kg} / \mathrm{dia}, 3 i d \\
50 \mathrm{mg} / \mathrm{kg} / \mathrm{dia} \text {, id }\end{array}$ \\
\hline & $\begin{array}{l}\text { Eritromicina } \\
\text { Claritromicina } \\
\text { Azitromicina }\end{array}$ & $\begin{array}{l}40 \mathrm{mg} / \mathrm{kg} / \mathrm{dia}, 4 i d \\
15 \mathrm{mg} / \mathrm{kg} / \mathrm{dia}, 2 i d \\
10 \mathrm{mg} / \mathrm{kg} / \mathrm{dia} \text {, id }\end{array}$ & & \\
\hline \multirow{3}{*}{$\begin{array}{l}4 \text { meses } \\
\text { a } \\
4 \text { anos }\end{array}$} & $\begin{array}{l}\text { Amoxicilina PO } \\
\text { Ampicilina EV }\end{array}$ & $\begin{array}{l}90 \mathrm{mg} / \mathrm{kg} / \mathrm{dia}, 3 \mathrm{id} \\
150 \text { a } 200 \mathrm{mg} / \mathrm{kg} / \mathrm{dia}, 3-4 \mathrm{id}\end{array}$ & $\begin{array}{l}\text { Amox-clav PO } \\
\text { Ceftriaxone EV }\end{array}$ & $\begin{array}{l}90 \mathrm{mg} / \mathrm{kg} / \mathrm{dia}, 3 i d \\
50 \mathrm{mg} / \mathrm{kg} / \mathrm{dia} \text {, id }\end{array}$ \\
\hline & & & $\begin{array}{l}\text { Flucloxacilina EV } \\
\text { Vancomicina EV }\end{array}$ & $\begin{array}{l}100 \mathrm{mg} / \mathrm{kg} / \mathrm{dia}, 3 i d \\
30 \mathrm{mg} / \mathrm{kg} / \mathrm{dia}, 3 i d\end{array}$ \\
\hline & & & $\begin{array}{l}\text { Claritromicina } \\
\text { Azitromicina }\end{array}$ & $\begin{array}{l}15 \mathrm{mg} / \mathrm{kg} / \mathrm{dia}, 2 \mathrm{id} \\
10 \mathrm{mg} / \mathrm{kg} / \mathrm{dia}, \mathrm{id}\end{array}$ \\
\hline \multirow[t]{2}{*}{$\begin{array}{l}\text { Superior ou } \\
\text { igual a } 5 \text { anos }\end{array}$} & $\begin{array}{l}\text { Amoxicilina PO } \\
\text { Ampicilina EV }\end{array}$ & $\begin{array}{l}90 \mathrm{mg} / \mathrm{kg} / \mathrm{dia}, 3 i d \\
150 \text { a } 200 \mathrm{mg} / \mathrm{kg} / \mathrm{dia}, 3-4 \mathrm{id}\end{array}$ & Ceftriaxone EV & $50 \mathrm{mg} / \mathrm{kg} / \mathrm{dia}$, id \\
\hline & $\begin{array}{l}\text { Claritromicina } \\
\text { Azitromicina }\end{array}$ & $\begin{array}{l}15 \mathrm{mg} / \mathrm{kg} / \mathrm{dia}, 2 i d \\
10 \mathrm{mg} / \mathrm{kg} / \mathrm{dia} \text {, id }\end{array}$ & $\begin{array}{l}\text { Flucloxacilina EV } \\
\text { Vancomicina EV }\end{array}$ & $\begin{array}{l}100 \mathrm{mg} / \mathrm{kg} / \mathrm{dia}, 3 i d \\
30 \mathrm{mg} / \mathrm{kg} / \mathrm{dia}, 3 i d\end{array}$ \\
\hline
\end{tabular}

id - número tomas por dia, PO - via oral, EV - via endovenosa, Amox-clav - Amoxicilina e ácido clavulânico. Adaptado de "Do we know when, what and for how long to treat? Antibiotic therapy for pediatric community-acquired pneumonia. Pediatr Infect Dis J 2012"

Quadro 6. Esquemas de antibioterapia recomendados em crianças com PAC.

orientações atuais da DGS, publicadas em 2015 (https://www.dgs.pt/directrizes-da-dgs/orientacoes-e-circulares-informativas/orientacao-n-0072015-de-26012015.aspx) recomendam a sua utilização nas primeiras 48 horas após o aparecimento dos sintomas em casos selecionados (critérios de gravidade clínica ou doença progressiva, em portadores de doença crónica grave ou descompensada e em doentes internados).

O seguimento das crianças com PAC baseia-se em critérios de gravidade, nas alterações radiológicas, na recorrência da doença e persistência dos sintomas.

A radiografia de tórax só necessita ser repetida se houver agravamento do quadro ou perante suspeita de complicações. Não é necessário controlo radiológico ou laboratorial em crianças previamente saudáveis e com boa evolução clínica. Nas pneumonias redondas (condensações) e complicadas, ou em caso de sintomas persistentes, o controlo radiológico devera ser efetuado quatro a seis semanas após a alta.

Nas crianças com PAC grave, empiema, derrame pleural complicado ou abcesso pulmonar é obrigatório o seu seguimento até à recuperação clinica e radiológica total ou quase total.

A prevenção da PAC é importante e possível. Devem ser fortemente recomendadas medidas de prevenção de contágio, como a lavagem das mãos. A imunização para Hib, Bp, Sp e influenza tem revelado eficácia na diminuição da 
incidência da PAC, devendo ser recomendada e monitorizada.

O aleitamento materno, dado que se associa a menor incidência e menor gravidade da PAC, deve ser incentivado.

\subsection{FACTOS A RETER}

As infeções do aparelho respiratório baixo são muito frequentes em idade pediátrica.

A BQL aguda manifesta-se tipicamente com um quadro de pieira febril, sendo o VSR responsável pela maioria dos casos. O diagnóstico é clínico, não estando por rotina indicados exames complementares. A maioria dos casos evolui sem complicações, apenas com medidas de suporte para manter oxigenação e hidratação.

A PAC caracteriza-se por febre e/ou sintomas respiratórios de início recente com evidência de envolvimento do parênquima pulmonar. A etiologia varia com a idade, sendo os principais agentes etiológicos os vírus respiratórios. O pneumococo é a bactéria mais frequente em crianças. A radiografia do tórax pode ser útil para confirmar o diagnóstico e avaliar a existência de complicações. Não estão recomendados outros exames complementares em casos de gravidade ligeira e sem necessidade de internamento. A decisão terapêutica deve ter em conta a idade, a clínica e os factores epidemiológicos. O antibiótico de primeira linha é a amoxicilina oral em dose elevada. A maioria dos doentes é tratado em ambulatório e evolui sem complicações.

\section{Leitura complementar}

Direção-Geral da Saúde. Norma no 016/2012 de 19/12/2012 atualizada a 23/02/2015. Diagnóstico e Tratamento da Bronquiolite Aguda em Idade Pediátrica. Direção-Geral da Saúde [Internet]. Disponível em: http://www.dgs. pt/directrizes-da-dgs/normas-e-circulares-normativas. aspx?cachecontrol=1469035919127

Ralston S, Lieberthal A, Meissner $\mathrm{H}$ et al. Clinical Practice Guideline: The Diagnosis, Management, and Prevention of Bronchiolitis. Pediatrics 2014;134:e1474-1502.

Direção-Geral da Saúde. Norma no 019/2012 de 26/12/2012.

Diagnóstico e Tratamento da Pneumonia Adquirida na Comunidade em Idade Pediátrica. Direção-Geral da Saúde [Internet]. Disponível em: https://www.dgs.pt/ directrizes-da-dgs/normas-e-circulares-normativas/ norma-n-0192012-de-26122012.aspx

Esposito S et al. Do we know when, what and for how long to treat? Antibiotic therapy for pediatric community-acquired pneumonia. Pediatr Infect Dis J 2012; 00:e78-85.

Watts K and Goodman D. Wheezing in infants: Bronchiolitis. In: Kliegman R, Santon B, St. Geme J, Schor N, Berhman R, editors. Nelson Textbook of Pediatrics. Philadelphia: Elsevier; 2011. p. 1456-59

Direção-Geral da Saúde. Norma no 012/2013 de 30/07/2013 atualizada a 28/12/2015. Prescrição de Palivizumab para Prevenção de Infeção pelo Vírus Sincicial Respiratório em Crianças de Risco Direção-Geral da Saúde [Internet]. Disponível em: http://www.dgs.pt/directrizes-da-dgs/normas-e-circulares-normativas.aspx?cachecontrol=1469035854932

Lower respiratory tract infection. In: Sharland M, editors. Manual of Childhood Infections The Blue Book. Oxford: Elsevier; 2011. p. 1456-59. 